\title{
Leveraging Private Capital for Climate Mitigation: Evidence from the Clean Development Mechanism*
}

\author{
Patrick Bayer ${ }^{\dagger}$ \\ University of Mannheim
}

\author{
Christopher Marcoux \\ DePauw University
}

\author{
Johannes Urpelainen \\ Columbia University
}

5 September 2013

\begin{abstract}
To mitigate climate change, states must make significant investments into energy and other related sectors. To solve this problem, scholars emphasize the importance of leveraging private capital. If states create institutional mechanisms that promote private investment, they can reduce the fiscal cost of carbon abatement. We examine the ability of different international institutional designs to leverage private capital in the context of the Kyoto Protocol's Clean Development Mechanism (CDM). Empirically, we analyze private capital investment in 3,749 climate mitigation projects under the CDM, 2003-2011. Since the CDM allows both bilateral and unilateral implementation, we can compare the two modes of contracting within one context. Our model analyzes equilibrium private investment in climate mitigation. When the cost of mitigation is high, unilateral project implementation in one host country, without foreign collaboration, draws more investment than bilateral contracting, whereby foreign investors participate in the project.
\end{abstract}

\footnotetext{
${ }^{*}$ This paper was written during a research stay funded by an ERP fellowship of the Studienstiftung des deutschen Volkes. Patrick Bayer gratefully acknowledges this generous funding and is thankful for the hospitality of Columbia University. We thank Michaël Aklin, Paula Castro, Kyle Meng, and Martin Stadelmann for helpful comments on a previous draft.

${ }^{\dagger}$ Corresponding author. Department of Political Science, University of Mannheim. D7, 27. 68131 Mannheim, Germany. Phone: +49-621-181-2418. Email: pbayer@mail.uni-mannheim.de
} 


\section{Introduction}

States often face resource constraints in supplying global public goods (Barrett, 2007). As one promising response to resource scarcity, scholars and policymakers have increasingly emphasized the importance of leveraging private capital (Kaul, 2006; Brinkman, 2009; Bernhagen and Mitchell, 2010; Rosendal and Andresen, 2011). ${ }^{1}$ In the case of climate mitigation, private capital investment can facilitate the decarbonization of the energy infrastructure especially in rapidly emerging countries. When states provide public funding for climate mitigation, they may create profitable investment opportunities for the private sector. To increase private investment in wind turbines, for example, states could offer a subsidy to wind electricity generators. This would produce climate mitigation at a lower cost than without private investment, increasing investors' willingness to act.

Under the Kyoto Protocol, the Clean Development Mechanism (CDM) provides revenues from sales of emission credits generated by mitigation projects in developing countries (Streck and Lin, 2008; MacKenzie, Ohndorf, and Palmer, 2012). Industrialized countries with Kyoto Protocol commitments have bought carbon credits from projects implemented in the developing countries, and this has increased the profitability of climate mitigation in the global South. However, leveraging private capital through public subsidies also presents challenges. Not only do investors demand a return for their efforts, they also worry about political and other risks associated with project implementation (Henisz, 2002; Büthe and Milner, 2008; MacKenzie, Ohndorf, and Palmer, 2012). This article examines what kinds of public-private partnerships can attract large amounts of capital from private investors under the CDM. ${ }^{2}$

We begin by developing a simple decision-theoretic model of capital investment. In the model, capital markets consider allocating capital to a project that would mitigate climate change in exchange for carbon credits. The capital markets are assumed to be private, so that investors focus on maximizing their net profits. Our main conceptual innovation is to distinguish between two types of contracting on climate mitigation. Unilateral implementation refers to the possibility that a for-profit project developer in a given country implements a project and then sells carbon credits from the project on global markets (Michaelowa, 2007).

\footnotetext{
${ }^{1}$ By "private capital," we refer to investments by corporations. This definition also includes companies with some state ownership.

${ }^{2}$ To be sure, leveraging private capital may not itself be a good empirical indicator of efficiency. Under profit maximization, a lot of private capital could be allocated to CDM projects that would have been implemented even without the CDM.
} 
The CDM now allows investors to acquire carbon credits from climate mitigation projects in the developing world. Alternatively, bilateral contracting refers to the possibility that the project developer directly cooperates with interested foreign investors on carbon abatement. This is also possible under the CDM. The key difference between these two types is the role of foreign investors. In unilateral implementation, they pay for them indirectly through markets. In bilateral contracting, they participate directly during project implementation.

The central advantage of bilateral contracting is that foreign governments can provide technical assistance and supply additional funding. However, bilateral contracting carries greater political risk. In bilateral contracts, foreign investors may face discrimination, and they have less information about local conditions than does the hosting project developer. Therefore, problems of credible commitment and asymmetric information are present. Our decision-theoretic model shows that bilateral contracting should suffer when the marginal cost of carbon abatement is high. Given high project costs per ton of carbon, the developer's informational advantage is pronounced because even small information advantages can prove decisive for profitability. Thus, bilateral contracts should only leverage additional foreign capital when the cost of climate mitigation is relatively low.

We then examine a dataset of 3,749 CDM projects from 2003 to 2011. In the CDM, domestic project developers can implement carbon abatement projects to secure carbon credits that can be sold to industrialized countries with Kyoto emissions reductions commitments. For example, an Indian energy utility could invest in wind power instead of less costly coal, and the CDM would allow it to sell carbon credits to Japan worth the difference in emissions that the investment made. The CDM allows both unilateral and bilateral implementation (Michaelowa, 2007; MacKenzie, Ohndorf, and Palmer, 2012). For example, the Indian utility could partner with an American bank to cover the fixed capital costs of the wind investment, and the American bank would then receive some of the carbon credits. Alternatively, the Indian utility could collaborate with a European wind turbine manufacturer. For industrialized countries, the CDM reduces the cost of climate mitigation, which in turn promotes the supply of climate mitigation.

The data have two unique features that allow us to implement a detailed test of our theory. First, the dataset indicates how much capital was leveraged relative to the amount of carbon abatement expected. Second, the dataset distinguishes between unilateral implementation by project developers and bilateral 
contracting between project developers and investors from industrialized countries who have incentives to reduce their carbon dioxide emissions. We find robust statistical evidence for our theory. Unilateral implementation draws much more private capital than bilateral contracting when the marginal cost of climate mitigation is high, but the difference between unilateral implementation and bilateral contracting disappears when climate mitigation is inexpensive.

If states are to draw private capital into climate mitigation, they should design international institutions that emphasize unilateral implementation when the expected cost of carbon abatement is relatively high. In such circumstances, bilateral contracting does not significantly increase the availability of private capital through foreign investment. It is only when carbon abatement is cheap that states should invest heavily in institutions that minimize the transaction costs of bilateral contracting. While bilateral contracting cannot solve the most difficult problems impeding climate mitigation, it can meaningfully improve carbon abatement in more conducive circumstances. Although private capital is not an end itself, it can expand the scale and scope of climate mitigation activities under carbon markets. The more readily private investors allocate capital to carbon abatement projects under the CDM, the higher the share of these cost-effective mitigation efforts in the global total is. This benefits industrialized states in the form of cost-effectiveness and developing countries in the form of investment and revenue from carbon credits.

In the case of the CDM, the benefits of foreign investment, such as technology transfer and foreign expertise, could be notable if the marginal abatement costs of possible projects in the horizon remain sufficiently low. This is important because it offers a rationale for implementing the CDM, despite difficulties associated with evaluating the additionality of carbon abatement and the possibility that CDM projects in host countries ultimately discourage developing countries from adopting commitments because the "low hanging fruit" has already been consumed (Castro, 2012). In the concluding section, the policy implications of the findings for the CDM are discussed in greater detail.

More generally, the article contributes to the study of relationships between public and private actors in international relations. In recent years, scholars have increasingly emphasized the role of private actors, such as international investors and multinational businesses (Sell, 2003; Jensen, 2003; Bernhagen and Mitchell, 2010; Büthe and Mattli, 2011). Exploring the relationship between institutional design (Abbott and Snidal, 1998; Barrett, 2003; Binder and Neumayer, 2005) and the possibility of leveraging private capital for climate 
mitigation (MacKenzie, Ohndorf, and Palmer, 2012), we offer theoretical and empirical contributions to this body of literature.

\section{Leveraging Private Capital for Climate Mitigation}

Recently, debates concerning climate mitigation and global problems more generally have emphasized the importance of the private sector (Kaul, 2006; Brinkman, 2009; Bernhagen and Mitchell, 2010). While firms have few incentives to reduce carbon emissions for the world, many climate mitigation projects also create profitable business opportunities, provided states pay for the incremental cost of reducing negative or producing positive externalities. If states decide to invest in carbon abatement, for example, they can leverage private capital by allowing investors to keep their profits. The value of public investment is increased by the private investment that follows.

Unfortunately, leveraging private capital for climate mitigation is not easy. If governments cannot credibly commit to regulations and subsidies that turn the supply of climate mitigation into a profitable enterprise, markets cannot help states (Lin, Ko, and Yeh, 2007; Brinkman, 2009). The problem is exacerbated by the fact that many of the most lucrative project opportunities are found in politically risky countries (Markusen, 2001; Henisz, 2002; Büthe and Milner, 2008). Many biodiversity hotspots are located in unpredictable countries, such as the Democratic Republic of Congo, whose governments cannot credibly commit to protect foreign investors' property rights. Investing in renewable energy is similarly difficult in countries that cannot reliably protect foreign property and technological innovation against theft and violent expropriation. MacKenzie, Ohndorf, and Palmer (2012) show, for example, that imperfect enforcement of contracts under the CDM creates a moral hazard problem that precludes efficient levels of investment.

Given these difficulties, the effectiveness of different strategies for leveraging private capital is an important question for climate mitigation. One key issue in the design of such strategies is the choice between emphasizing bilateral and unilateral implementation. However, the relative merits of bilateral and unilateral project implementation are poorly understood. Although there is now a substantial literature on publicprivate partnerships and private governance (Gulbrandsen, 2004; Kaul, 2006; Bernhagen and Mitchell, 2010; Büthe and Mattli, 2011), earlier research has not developed explicit models to compare bilateral and unilateral modes of project implementation. In the literature on the Clean Development Mechanism (CDM), the 
difference between bilateral and unilateral implementation is recognized (Dinar et al., 2011; Winkelman and Moore, 2011; World Bank, 2011). For example, these studies note that the unilateral implementation of mitigation projects has become increasingly popular. However, the literature does not examine the consequences of unilateral implementation for leveraging private capital.

An important exception to this trend is Michaelowa's (2007) study of unilateral CDM. He emphasizes two aspects of the problem. First, political risks and transaction costs often deter foreign investors from participating directly in project implementation. Therefore, unilateral implementation has become increasingly popular. Accordingly, Lütken and Michaelowa (2008) show that the importance of unilateral implementation for the CDM has indeed increased over time. Moreover, unilateral CDM is mostly focused on rapidly industrializing democratic countries, such as India, while bilateral CDM dominates project implementation in the least developed countries. This is understandable given that in the least developed countries, capital markets may not function well and the number of available, competent project developers may be low. However, Lütken and Michaelowa (2008) do not examine how unilateral implementation influences the availability of private capital.

In the case of China, Maraseni and Xinquan (2011) provide evidence for the claim that unilateral implementation reduces political risk and transaction costs for interested investors. However, it remains unclear whether their findings are valid outside China and whether the advantages of unilateral implementation outweigh the costs, including reduced technology transfer and lack of external capacity building. In addition to illuminating the general trade-off between unilateral implementation and bilateral contracting, the theoretical model presented in the next section allows us to examine the consequences of unilateral implementation in the context of the CDM.

\section{Private Investment in Climate Mitigation for Carbon Credits}

We rely on a simple decision-theoretic model to analyze the possibility of private capital investment in carbon abatement. In the model, projects produce two different profit streams. First, there are direct profits, such as reduced energy consumption following efficiency improvements. Second, projects may generate credits that can be sold on global markets. For example, energy efficiency improvements mitigate climate change, so they qualify for carbon credits. To evaluate the financial feasibility of the project, we compare 
the total value of these profit streams to the risk of project failure and costs of project implementation. If implemented, the project is assumed to generate genuine emissions reductions, so that the problem of non-additionality is ignored.

We examine how much investment can be secured under unilateral and bilateral modes of contracting, as defined in the introduction. In unilateral implementation, project developers are essentially private investors who maximize their profits by investing their capital in the local economy. In the CDM, for example, project developers could be factories in developing countries that invest in energy efficiency measures to reduce their production costs and gain carbon credits. While these projects face political-economic risks, they do not suffer from risks associated with foreign direct investment, such as asymmetric information and discrimination against foreign investors.

In bilateral contracting, a domestic investor in a developing country finds an international partner, and they collaborate to jointly implement the project. For example, a Chinese factory interested in energy efficiency could collaborate with a European company that has access to advanced energy conservation technologies. Alternatively, the Chinese factory could find a European bank that would cover some of the project's fixed capital costs and write a contract to gain some proportion of the carbon credits. Political and other project risks can be expected to be higher because the participation of a foreign investor raises the possibilities of discrimination against foreign investors and information asymmetries.

We examine if unilateral implementation is more profitable because domestic developers are less vulnerable to political risk than foreign investors. Building on this insight, we can examine if bilateral contracting can leverage significant amounts of private capital for climate mitigation. If unilateral implementation is significantly more profitable, then developing institutions for bilateral contracting is not worthwhile. If unilateral implementation does not hold a significant advantage, then bilateral contracting can expand access to private capital, thereby increasing climate mitigation.

\subsection{Feasibility of Project Investment}

Consider a project that requires a total capital cost of $c>0$ during the implementation period. For example, in the case of climate mitigation an increase in $c$ would capture increased marginal abatement costs, perhaps because the carbon intensity of the economy would decrease. The less carbon an economy emits relative to 
its gross domestic product, the harder it is to find low-cost substitutes for carbon. Thus, the marginal cost of climate mitigation increases. Similarly, $c$ could contain information about the transaction cost of project implementation (Michaelowa, 2007). If the project succeeds, it produces a gross profit $\pi>0$. This profit captures the total value of the project, the capital cost notwithstanding. For example, it could reflect both the direct value of a climate mitigation project, such as selling renewable electricity to consumers, and the value of the resulting carbon credits on global markets.

As we consider the feasibility of project implementation, we assume capital markets exist. This means that our focus is not on any particular investor's decision. Rather, we examine whether any of a possibly large number of investors would be willing to implement the project. This assumption accords with the principles underscored in the literature on leveraging private capital for climate mitigation. The question is not if any particular investor is willing to implement a project, but if capital markets can mobilize enough resources for project implementation. ${ }^{3}$

The project also carries risks. Let $p \in(0,1)$ denote the probability of project success. For example, the project could fail if the host country's regulators decide to prevent implementation. As these risks decrease, the probability of success $p$ increases. Under this simple framework, the project can be implemented if capital markets can expect a net profit. This means that the difference between the expected benefit and project cost must exceed the value of alternative investment opportunities, normalized to zero without loss of generality. Thus, our model assumes investors are savvy: they consider alternative investment opportunities.

Formally, the following condition determines the financial feasibility of the project:

$$
p \pi \geq c
$$

In plain English, the expected benefits $p \pi$ must exceed the costs $c$. If this condition is met, the project is profitable enough that, in equilibrium, an investor for the project is found. In what follows, we characterize the determinants of the risk parameter $p$ and derive empirical implications from this characterization. ${ }^{4}$

\footnotetext{
${ }^{3}$ Formally, one might assume that a continuum of investors with different preferences exists. Our decision-theoretic model would examine whether at least one of these investors has an incentive to provide capital for the project.

${ }^{4}$ For simplicity, investors are assumed to be risk-neutral. In the appendix, we show the results also hold for risk-averse investors.
} 


\subsection{Unilateral and Bilateral Implementation}

The main difference between unilateral and bilateral implementation lies in the project's risk component. In considering this risk, we hold the environmental integrity of the project constant and examine the ability of unilateral and bilateral implementation to avoid project risks. In other words, we examine if unilateral or bilateral implementation can implement projects of a given environmental value more cost-effectively due to lower risk. For unilateral implementation, foreign beneficiaries of the project purchase credits on global markets, without being involved in a project. Therefore, the project's profitability is not influenced by political-economic risks associated with foreign direct investment. With bilateral implementation, the project depends on the participation of foreign investors, whose decisions are critical. ${ }^{5}$

There are several reasons why the participation of foreign partners should be associated with higher risk. First, the host government has fewer political incentives to help foreign partners generate profits. The literature on foreign investment often emphasizes political risks, such as discrimination and expropriation (Jensen, 2003). Even though flagrant forms of investment discrimination, such as nationalization, have decreased over time, concerns about the investment environment remain a major obstacle to increased investment (Henisz, 2002; Büthe and Milner, 2008; Kerner, 2009). Since the government is not politically accountable to foreign partners, it may be tempted to extract more rents from foreign partners than from domestic developers, which can more directly influence the government's political fortunes. ${ }^{6}$

Second, the presence of a foreign partner may create problems of asymmetric information. Specifically, the domestic project developer may have an informational advantage over the foreign partner regarding the risks and profitability of the project (MacKenzie, Ohndorf, and Palmer, 2012). Since the foreign partner may not have enough information about the local context due to a lack of experience, its actions may not be based on accurate information about host country conditions (Tallman, 1992). In this case, the foreign

\footnotetext{
${ }^{5}$ Unilateral and bilateral implementation assign a different role to foreign investors: passive in unilateral, active in bilateral. Therefore, we cannot compare a specific investor's choice across unilateral and bilateral implementation. However, we can compare the availability of private capital in the aggregate. An individual investor's decision is not as important as the capital market's aggregate ability to supply capital for project implementation. Conceptually, this is identical to the basic microeconomic analysis of aggregate demand and supply in standard goods markets.

${ }^{6}$ The size of this effect may depend on the political-economic clout of the foreign partner. Large multinational corporations may, by virtue of their resources, be able to resist discrimination by the host country's government. However, this is ultimately an empirical argument. Unless the foreign partners hold a drastic advantage in terms of their resources, domestic developers should have an advantage on the margin. The size of this advantage is again an empirical question that cannot be resolved on a theoretical basis, and our empirical findings suggest that the domestic developers' advantage is indeed large.
} 
partner may hesitate to invest without additional and costly information revelation by the partnering local host. This increases the total negotiation cost and thus contributes to project risk. ${ }^{7}$

Finally, bilateral implementation may create bargaining problems. While unilateral projects are implemented by a single project developer, who at most has to negotiate with domestic players, bilateral projects require negotiations between the domestic project developer and a foreign partner. These negotiations may be delayed, or even fail, if one of the partners decides to "hold out" in view of securing greater concessions from the other (Williamson, 1979).

To complete the discussion, it is important to consider counterarguments. There are some seemingly plausible reasons to believe foreign partners may simply have an advantage in finding inexpensive projects that carry low risks. One is their ability to search profitable carbon abatement opportunities across different host countries. In practice, this advantage is probably small. Given the high transaction cost of negotiating a partnership with a local developer, it is difficult for a foreign partner to threaten to move to another country in the negotiations. Moreover, the local developer can also simply threaten to collaborate with another foreign partner. Another possibility is that the foreign investor can secure capital more easily than the domestic developer due to a better reputation. We expect this benefit to be relatively limited, given that the foreign investor will have to work with a domestic developer in any case.

Due to the higher political risk that accompanies bilateral project implementation, we assume that the ex ante probability of success for unilateral projects, $p_{u} \in(0,1)$, is higher than the probability of success for bilateral projects, $p_{b} \in(0,1)$. Formally, we assume $p_{u}>p_{b}$. Empirically, this assumption does not mean that a given unilateral project is always less risky than a given bilateral project. Projects are highly heterogeneous and the risks associated with them vary widely, regardless of the mode of implementation. We, however, expect the unilateral-bilateral difference to be important on the margin.

By focusing on political-economic risks, which favor unilateral implementation, we can identify the relative advantage of unilateral over bilateral implementation. If this advantage is large, then states should invest in creating international institutions that promote unilateral project implementation, such as carbon markets. If the advantage is small, then institutions for bilateral implementation are optimal. After all, bilateral implementation also has benefits, such as increased technology transfer (Bayer and Urpelainen, 2013)

\footnotetext{
${ }^{7}$ To be sure, it is possible that bilateral implementation allows domestic developers to capitalize on foreign expertise. However, this expertise would simply create another problem of asymmetric information, further complicating bargaining.
} 
and the possibility of external capacity building. While our model does not emphasize these benefits, their presence is important because otherwise unilateral implementation would dominate bilateral implementation by definition. ${ }^{8}$

\subsection{Testable Implications}

Our two-part hypothesis from the model is that unilateral project implementation has a particularly large advantage vis-à-vis bilateral contracting if project costs $c$ are high. To derive this hypothesis, note that slight manipulation of equation (1) gives

$$
\pi \geq \frac{c}{p}
$$

Intuitively, this expression shows the "investment threshold" for $\pi$, defined as the lowest total value of the project's benefits $\pi$ that allows profitable investment. Whenever $\pi$ exceeds the ratio of project cost to the success probability, $\frac{c}{p}$, capital markets invest in the project. Higher probabilities of project success $p$ make investment more likely, ceteris paribus. At the same time, the size of the marginal effect of an increase in a project's success probability is increasing in project costs $c$. Formally, the marginal effect of changes in $p$ on the lowest value of $\pi$ that allows investment is $-\frac{c}{p^{2}}$. The absolute value of this effect is increasing in $c$.

Given that probabilities for successful unilateral contracting $p_{u}$ are higher than those for bilateral contracting $p_{b}$, the interactive effect of $p$ and $c$ has two important implications. First, the marginal effect of moving from bilateral implementation, with a relatively low success probability $p_{b}$, to unilateral implementation, with a higher success probability $p_{u}$, has a larger effect on the attractiveness of investment when project costs $c$ are sufficiently high. For expensive projects, unilateral implementation draws significantly more private capital than bilateral implementation. However, the comparative advantage of unilateral contracting over bilateral contracting decreases as project costs $c$ decrease. This also follows directly from the fact that the size of the negative marginal effect of increasing $p$ on the investment threshold is decreasing in c. Intuitively, if project costs are low, capital markets are not as sensitive to changes in success probabilities $p$ as when costs are high. This allows us to derive our two-part hypothesis:

\footnotetext{
${ }^{8}$ To be sure, bilateral contracting may also mitigate against one type of project risk. If a contract is formed, the local project developer may not have to worry about price risk. Our theory is based on the assumption that more fundamental project risks, such as implementation failure, are more important than price risk. Moreover, bilateral contracting on price may be difficult if the foreign partner believes that the local project developer holds private information.
} 
Hypothesis 1. If the cost of project implementation $c$ is high, unilateral implementation draws significantly more private capital than bilateral contracting. As the cost of project implementation c decreases, the advantage of unilateral implementation over bilateral contracting in drawing private capital decreases.

The logic behind our hypothesis is illustrated in Figure 1. For a given success probability of bilateral implementation $p_{b}$, the figure shows how much the investment threshold for $\pi$ decreases for different project costs $c$ if unilateral implementation is used instead of bilateral implementation. Lower values suggest large advantages of unilateral implementation over bilateral implementation. As the figure shows, the advantage of unilateral implementation increases with project $\operatorname{costs} c$. Given high project costs, the reduced politicaleconomic risk from unilateral implementation is highly valuable for leveraging climate capital.

[Figure 1 about here.]

\section{Research Design}

Testing our theory requires data on climate mitigation projects implemented by project developers. In particular, we need detailed data on how much private capital was made available for a project of a given size. Additionally, the data must exhibit variation in the mode of contracting while holding other contextual factors constant. In view of these requirements, the CDM presents an ideal opportunity. ${ }^{9}$ The purpose of the $\mathrm{CDM}$ is to reduce the cost of climate mitigation in industrialized countries by allowing them to substitute "carbon credits" for costly domestic mitigation. Credits are acquired from climate mitigation projects in developing countries, where the cost of pollution abatement is often lower than in industrialized countries.

Since the CDM allows both unilateral and bilateral implementation, it allows us to test our theoretical argument within one context. Initially, the CDM only allowed bilateral implementation. Aware of the potential value of carbon credits, a number of developing countries suggested they should be allowed under the $\mathrm{CDM}$ to finance project implementation within their own borders, earning emission credits even without the presence of Annex B investment. While the legality of such unilateral implementation was initially unsettled under the CDM, in 2005 the Executive Board of the CDM adopted a resolution specifically permitting unilateral implementation (Michaelowa, 2007). ${ }^{10}$

\footnotetext{
${ }^{9}$ See http: / / cdm. unf ccC. int/index. html for the CDM. Accessed January 19, 2012.

${ }^{10}$ For details of CDM project implementation, see our appendix.
} 
Project data are provided by the CDM/JI Pipeline Database maintained by the United Nations Environment Programme. ${ }^{11}$ Our dataset covers 3,749 projects that were registered, waiting for registration, or at the validation stage between 2003 and 2011. While most projects are located in China $(1,939)$ and India (823), Brazil and Malaysia also host more than 100 projects each. ${ }^{12}$ For each project, variables are coded consistently provided at the time of registration. ${ }^{13}$ In total, our sample includes 55 different countries in all regions of the world. ${ }^{14}$

\subsection{Dependent Variable}

We examine how much private capital investors are willing to supply under bilateral and unilateral contracting. Accordingly, the dependent variable is the amount of private capital invested for each ton of mitigated carbon dioxide. By a ton of mitigated carbon dioxide, we refer to expected emissions reductions in tons of carbon dioxide equivalent relative to the additionality baseline by the year 2020, as defined in the database. The data are based on the project design documents and refer to expected total investment during the project. This variable can be thought of as a proxy for investors' willingness to pay for carbon abatement, relative to the size of the project. Previous research has focused on the geographic distribution of projects (Dinar et al., 2011), and thus does not shed light on investors' willingness to invest. It remains unclear whether and how the mode of contracting influences investors' willingness to pay for carbon abatement in individual projects. Therefore, it is useful to examine investment behavior with single projects as the unit of analysis. ${ }^{15}$

Of course, the resulting ratio of investment to carbon abatement is higher than the marginal carbon abatement cost. CDM projects generate many other benefits than carbon credits, and investors consider these in their decisions to allocate capital. Indeed, our data clearly show that the investment per ton of carbon dioxide is much higher than the marginal abatement cost, often by a magnitude. This is as expected, given the direct profits from CDM projects, such as sales of renewable electricity.

\footnotetext{
${ }^{11}$ See http: / / cdmpipeline.org. Accessed January 19, 2012.

${ }^{12}$ For a list of the top $10 \mathrm{CDM}$ host countries, see our appendix.

${ }^{13}$ Here, we include terminated and rejected projects. Below, we also analyze a sample excluding these projects.

${ }^{14}$ Regionally: Asia and Pacific (3,206 projects), Latin America (422 projects), Africa (76 projects), Europe and Central Asia (17 projects), and the Middle-East (28 projects).

${ }^{15}$ In the appendix, we show that our results are also reasonably robust when aggregating data to the country level and estimating cross-sectional OLS models. This is particularly true when we re-weight each country's variance with the inverse of CDM project counts.
} 
Since our dataset includes both the amount of carbon avoided by a particular project and the total investment, we can construct our dependent variable as a ratio of the two. The data are not normally distributed, so we logarithmize the dependent variable. Given this logarithmization, the distribution is approximately normal, as shown in the appendix. However, some outliers remain. We exclude these from our analyses in a robustness check provided in the appendix.

\subsection{Independent Variables: Contracting Mode and Marginal Abatement Cost}

We examine the interactive effect of two independent variables. Our primary interest lies in the effect of contracting strategy on the supply of private capital for a project at different marginal abatement costs, as shown in the above hypothesis. Since we do not expect unilateral implementation to have an advantage at low marginal abatement costs, an interaction term must be included in all regressions. We are interested in the unilateral-bilateral difference at various levels of marginal abatement costs, and only a product term allows us to evaluate such conditional effects.

The CDM database indicates whether a project was implemented unilaterally or based on a formal emission reduction purchase agreement (ERPA) with a foreign partner. These partners are mostly financial institutions and large corporations; for them a purchase agreement is essentially a commitment to pay for project implementation. As Michaelowa $(2007,21)$ puts it, "[w]ith the conclusion of an ERPA the buyer commits to purchasing a certain amount of future CERs [Certified Emission Reductions] at a specific price" and that "the ERPA assigns the price risk and the Kyoto risk to the [...] buyer."

Following previous research (Michaelowa, 2007; Dinar et al., 2011), all projects with an ERPA by the project's validation date are considered bilateral. All other projects are considered unilateral. Ideally, we would also include data on the existence of an ERPA at registration or later, but such data are not available. ${ }^{16}$ We recognize that this coding is imperfect: an ERPA may contain a shallow commitment by the foreign partner, and a project without an ERPA may feature foreign involvement. As Michaelowa (2007) notes, no unambiguous definition of a unilateral project is possible: foreign participation has myriad forms and degrees. In addition to capturing an important form of project risk, our definition has the major advantage

\footnotetext{
${ }^{16}$ This coding cannot handle the possibility that an ERPA is formed later, such as upon registration. Such data are not available because the CDM database does not monitor individual projects continuously. However, even in cases of a late ERPA, the project developers did not have a purchase agreement at the time they submitted the project for registration.
} 
of being objective and available for all CDM projects. Data for more nuanced distinctions require subjective coding and are not available for the entire sample.

CDM project number 2175 (“24MW Perla Mini Hydel Project, Karnataka, India”) exemplifies unilateral implementation. ${ }^{17}$ The purpose of this project was to promote clean energy production through the creation of a hydroelectric generator in the Netravathi river in India, with annual expected carbon reductions of 59,299 tons over ten years. The electricity would then be sold to a state government-owned utility company. In this case, the investor that stands to earn these CERs for this project is a domestic firm: AMR Power Private, Ltd, of Hyderabad, India. For this large-scale hydroelectricity project, aggregate investment totals Rs 971 million (about US\$ 16 million) ${ }^{18}$, which will be used to cover construction costs involving the payment of wages, construction materials, and construction equipment on site; electro mechanical equipment is estimated to cost about Rs 480 million (about US\$ 8 million). Funding for this investment comes from equity and term loans, to be fully paid back during the first ten years of operation.

Now consider CDM project number 4852 ("Rakchad Small Hydro Electric Project”), which is similar to the above project in many respects and involves the financing of a small-scale hydroelectric power project to benefit a public utility, the Himachal Pradesh State Electricity Board. ${ }^{19}$ It comes with a capital cost of about Rs 310 million (about US\$ 5 million), 30\% of which are financed by equity shares and $70 \%$ by a term loan with $13 \%$ interest rate. However, unlike the project in Karnatka, the project in Rakchad is jointly run by Regent Energy, Ltd, as the Indian host, and Agrienergy, Ltd, of the United Kingdom as the foreign partner, both of which are registered as project partners on equal terms. For this project with its estimated annual carbon reductions of 22,605 tons of $\mathrm{CO} 2$ equivalents, over a seven-year crediting period, foreign investment and consultancy services originate from an Annex B country; therefore, this latter hydro project exemplifies bilateral implementation.

Clearly, the choice between unilateral and bilateral project implementation is endogenous to some extent, so that selection effects have to be considered. Importantly, our formal model can account for this: the empirical expectations coming from the decision-theoretic model are valid even though investors behave

\footnotetext{
${ }^{17}$ See http://cdm. unfCCC.int/Projects/DB/DNV-CUK1218551904.34/view for detailed project documentation. Accessed July 8, 2013.

${ }^{18}$ We used a 60.96 rupees per US dollar exchange rate, dating from July 8, 2013.

${ }^{19}$ See http: //cdm. unfCCC. int/Projects/DB/DNV-CUK1254893204.97/view for detailed project documentation. Accessed July 8, 2013.
} 
strategically. Since our theory accounts for this type of endogeneity, reverse causality from strategic behavior does not threaten the validity of our hypothesis test. ${ }^{20}$

Moreover, it is clear that global competition for cost-effectiveness characterizes both unilateral and bilateral implementation. In bilateral implementation, competition occurs between project developers looking for foreign partners. In unilateral implementation, carbon credits are sold in highly competitive markets. In this regard, there is no difference between the two modes of implementation.

China also deserves special mention. In China, almost all projects are formally bilateral due to legislation that requires an ERPA. In practice, however, many Chinese projects are essentially unilateral. To our understanding, no such legislation exists in any other country. In the appendix, we replicate our analysis excluding China, and show that this unique case does not drive our results.

To illustrate the effect of contracting mode on our dependent variable, Figure 2 shows the annual mean of project investments for unilateral and bilateral projects separately. Unilateral projects draw much larger amounts of private capital. This could be for various reasons, including project type and contracting risk. For the 967 unilateral projects in our sample, the overall mean investment is US\$ 660 per ton of carbon dioxide, while the mean investment in the 2,782 bilateral projects is only US\$ 335 per ton of carbon dioxide. These numbers differ from marginal abatement costs by an order of magnitude, suggesting that investment is not a proxy for marginal abatement cost. This is consistent with the notion that CDM projects also produce other types of profits.

[Figure 2 about here.]

Our second independent variable is intended to capture the marginal abatement cost in a host country at a given time. Marginal abatement costs are associated with the reduction of an additional unit of carbon emissions given current abatement levels. This implies that marginal abatement costs depend on the opportunities to reduce carbon.

We measure a country's marginal abatement costs using the national economy's carbon intensity. Since carbon intensity is defined as the ratio of carbon emissions to aggregate economic output, it captures the idea that the cost of abatement increases as carbon emitted for each unit of economic output decreases. If an

\footnotetext{
${ }^{20}$ Of course, this does not mean that there could not be other causes of endogeneity. We have selected our specifications and robustness tests to guard against this possibility, in particular by avoiding potentially endogenous regressors.
} 
economy is already characterized by low carbon intensity, reducing emissions requires major investments in new production technologies. This is more costly than reducing high emissions resulting from wasteful energy production or use. That is why it is costlier to reduce CO2 emissions in Sweden or Japan, which rank among the least carbon intensive industrialized economies, than in China or India. It would clearly be better to have disaggregated data on marginal costs by project, but this is not possible for a global dataset with thousands of projects. Even at the national level, marginal abatement cost curves are not available for most countries in our sample. For example, Castro's (2012) recent analysis of marginal abatement costs only focuses on eight countries due to data limitations. We cannot conduct our analysis with such a small sample. Besides problems of data availability, Kuik, Brander, and Tol (2009) show that estimates of marginal abatement cost curves are generally very sensitive to modeling assumptions and come with extremely large confidence bounds around the mean estimate, clearly falling below conventional standards of good practice in econometrically sound data analysis.

Abatement costs vary significantly across project types (Castro, 2012), and different types of projects feature different levels of risk (Balatbat, Findlay, and Carmichael, 2012). For example, solar power is mostly more expensive than hydroelectricity. Projects to combat deforestation may be more complex and produce less predictable results than renewable energy generation. We control for these effects by including fixed effects for project type. In one of the robustness checks, we even include detailed type fixed effects for 23 separate categories.

We divide carbon dioxide emissions, measured in millions of tons, by gross domestic product, measured in constant U.S. dollars with 2000 prices. We also use a three-year moving average to avoid conflating structural factors and random variation across time. We lag carbon intensity by two years because we only have carbon intensity data up to year 2009 and many CDM projects were implemented in 2011. This helps us avoid losing a large number of observations. Additionally, carbon intensity varies much more across countries than over time, so time lags and moving averages are appropriate. For example, the value of this independent variable would be the mean of the years $(t-3),(t-2),(t-1)$ for a project implemented at time $t$.

Our cost measure may suffer from two problems. First, investment per ton of carbon dioxide is obviously related to the size of the project. In addition to controlling for the size classification of projects in the main 
analysis, the appendix reports additional models that include an interaction between implementation mode and the expected carbon abatement from the project. The results clearly show that our finding is not driven by size bias. Another potential issue concerns project types. While controlling for project type in our main analysis, we replicated our findings for hydroelectricity projects (1,232 projects in the full sample) as the largest category, excluding all other projects, and found that our results remained unchanged. This suggests that our results are not driven by bias from heterogeneous effects across project types. ${ }^{21}$

\subsection{Control Variables}

The availability of private capital for project implementation depends on a variety of factors other than the mode of contracting and marginal abatement costs. While we use a parsimonious, theoretically informed set of control variables in our main model, we provide additional robustness tests, including additional covariates, in the appendix. Our main model incorporates three different control variables: corruption, regime type, and GDP.

To account for a country's quality of governance, we include a measure of government corruption from the International Country Risk Guide. We do so to control for the possibility that weak government institutions may inhibit investment in projects. ${ }^{22}$ In the context of CDM, where project risks are generally high, investors consider the institutional environment of target countries. Higher values on the corruption measure indicate more corruption. In our dataset, countries such as Singapore or Chile are classified as low corruption countries, while countries such as Guatemala or Nigeria are classified as states with high corruption levels. Again, we use a three-year moving average lagged by two years to avoid losing the years 2010-2011. For a project implemented at time $t$, the value of the control variable is the mean for the years $(t-3),(t-2),(t-1)$.

We also include a lagged binary indicator for regime type (Cheibub, Gandhi, and Vreeland, 2010). Democratic countries have stronger incentives to supply environmental public goods to their constituencies (Bueno de Mesquita et al., 2003). Accordingly, they may be more willing than non-democracies to support

\footnotetext{
${ }^{21}$ For the second and third largest renewable project types, wind ( 801 projects in the full sample) and biomass (377 projects in the full sample), we do not find evidence for our hypothesis. This probably reflects the reduction of the sample size to about 20 percent and 10 percent of the original dataset for wind and biomass projects, respectively. Our results do hold, however, if we exclude wind and biomass projects from our main analysis.

${ }^{22}$ See http: / /www.prsgroup.com/ICRG_Methodology.aspx. Accessed January 19, 2012.
} 
private investment in climate mitigation projects. After all, many climate mitigation projects produce local environmental and economic benefits as well.

Our third control variable is the logarithm of a country's GDP. Wealthy countries may afford more capital for climate mitigation, but it could also be that wealthy countries offer more profitable alternatives for investment. Thus, the opportunity costs to invest into carbon reduction projects may be too high in relatively wealthy countries. In our sample, this issue is critical because many of the wealthier countries are newly industrialized states. Whether GDP has a positive or a negative effect on investment behavior depends on a country's level of development. Even though we do not have a clear expectation for this variable, it is important to control for GDP in our analyses. For consistency, we again include GDP as a three-year moving average with a two-year lag. ${ }^{23}$

To these controls, we add two sets of fixed effects. First, we aggregated projects into nine major categories, following the codes provided in the CDM Pipeline guidance document. ${ }^{24} \mathrm{We}$ distinguish projects that target renewable energies (2,444 projects), the coal and cement sector (630 projects), energy efficiency on the supply (434 projects) and demand side (90 projects), fuel switching (91 projects), HFC and N20 reductions (38 projects), reforestation (11 projects), transport (10 projects), and CO2 usage (1 project). Controlling for project type is important because different project types require substantially different capital investments. While carbon emissions can be reduced relatively cheaply in projects with low capital input, e.g., reforestation, setting up a wind farm or installing a large hydroelectricity dam requires a lot of private capital. Failure to control for project type might lead one to wrongly attribute differences in our dependent variable to other variables. In the appendix, we show that the results hold even if we use a more refined classification with 23 categories.

Second, we include year fixed effects in all models. The lucrativeness of projects depends on the size and prospects of the global carbon market, and these have varied dramatically over the period of investigation. The World Bank's 2011 report on the "State and Trends of the Carbon Market" shows that the value of assets traded in the primary CDM market tripled from US\$2.6 billion in 2005 to US\$ 7.4 billion in 2007, only to

\footnotetext{
${ }^{23}$ In a robustness check, we also include the square of GDP to account for the environmental Kuznets curve. Results are unchanged.

${ }^{24}$ These are given in Table 11 of the "Analysis" tab in the CDM Pipeline spreadsheet that can be downloaded from the UNEP website. See http://cdmpipeline.org/cdm-projects-type.htm. Accessed February 9, 2012.
} 
see a rapid decline in the following years (World Bank, 2011, 9). These changes in the global market for carbon credits underscore the need for year effects in our model specification.

In the appendix, we present summary statistics for our main variables and controls. The first subtable shows them for the full sample, while the two other subtables present them separately for unilateral and bilateral projects. One notable difference between unilateral and bilateral projects is that the former are more common in democracies and countries with low carbon intensities. This may reflect differences in autocratic and democratic economic freedom. The latter observation is consistent with our argument: unilateral projects should have a significant advantage in countries with generally low carbon intensity, because in these countries project implementation is relatively costly. The flip side of this is that foreign capital is allocated into more risky bilateral projects only if higher risks are compensated with lower project costs. This is reflected in higher average carbon intensities and, by our argument, in lower marginal abatement costs in host countries for bilateral CDM projects.

We also present correlation matrices for these samples in the appendix. Notably, our dependent variable is positively and significantly correlated with carbon intensity. This is as expected, because high carbon intensities create profitable opportunities for mitigation. Our dependent variable is also positively and significantly correlated with the indicator for a unilateral project. This is as expected because domestic project developers have an information advantage and can better assess project risks that result from political, cultural, and social determinants. This may imply that domestic developers assign higher success probabilities to specific projects compared to their foreign counterparts. They invest more in the same projects as they face lower uncertainty. This relationship is revealed in the positive correlation coefficient between unilateral contracting and investments per ton of carbon dioxide.

\subsection{Matching on Contract Type}

To enhance the reliability of our empirical analysis and to avoid bias due to nonlinear effects, we implement a matching analysis (Iacus, King, and Porro, 2012). Specifically, our matching technique is designed to ensure covariate balance between unilateral and bilateral projects. As our correlation matrix from the appendix shows, the contracting mode variable is not randomly assigned. For example, it is highly correlated with democracy and corruption. This can pose a problem for our analysis if the effect of contracting mode on our 
dependent variable is nonlinear: merely controlling for covariates would be insufficient to disentangle the "treatment" effect (Morgan and Winship, 2010). Matching allows us to pre-process the data in such a fashion that unilateral and bilateral projects are comparable, while observations without a match are discarded. As shown in the appendix, matching greatly reduces the covariate imbalance in our sample, yet the results continue to hold.

\section{Findings}

We first discuss the primary findings from the statistical analysis and substantive effects. Next, we examine the robustness of our findings.

\subsection{Main Results}

Our main results are presented in Table 1. The first two models include our full sample. Model (1) presents the results for our main independent variables only, while model (2) also adds corruption, the binary regime type indicator, and GDP. Models (3) and (4) follow the same pattern, excluding China from our sample. Models (5) and (6) exclude India. ${ }^{25}$ All models are estimated with year fixed effects and project fixed effects to account for temporal changes in global carbon markets and systematic project heterogeneity, respectively. All standard errors are clustered by country.

[Table 1 about here.]

We hypothesize that the comparative advantage of unilateral projects in acquiring private capital is greatest when costs for project implementation are high. As we argued above, project implementation is expensive in host countries with low carbon intensities. Therefore, we can read the strong positive effect of our unilateral dummy on investments per ton of $\mathrm{CO} 2$ as supporting our hypothesis. This effect is highly significant and consistently so for all our model specifications. It also survives severe reductions of sample size when we exclude Chinese and Indian projects.

\footnotetext{
${ }^{25}$ In the appendix, we estimate the main model while excluding CDM projects from both China and India. Our results are not affected.
} 
The negative and persistently significant interaction effect of the dummy for unilateral projects and $\mathrm{CO} 2$ intensity provide evidence for the second part of our hypothesis. Unilateral projects attract high levels of private funds when project costs are high, but as costs decline, i.e., as carbon intensity increases, this vanishes. The relationship depicted in Figure 1 above can be seen in the interaction term's negative coefficient.

Regarding controls, it is interesting that both corruption and democracy do not seem to matter for investment choice. Intuitively appealing claims that democratic countries benefit from larger capital inflows due to higher political reliability, or that corrupt governments suffer from capital flight are not corroborated. For GDP, we find a significant negative effect; it seems that wealthier countries in our sample can offer more attractive investment possibilities than carbon abatement projects. Therefore, investments per ton of carbon dioxide are lower in richer countries than in poorer ones.

We show the marginal effect of unilateralism on investment, conditional on the host country's carbon intensity in Figure 3. ${ }^{26}$ We present our results for the entire sample of 3,749 projects, as well as for the subsamples excluding China and India. Figure 3 clearly indicates that the negative interaction effect is not driven by one single country, but is a pattern that is consistently found across subsamples.

[Figure 3 about here.]

These plots demonstrate that the negative interaction effect translates into a substantively meaningful effect. The marginal effect of unilateralism is strictly positive for low carbon intensities in all three subsamples, yet it is no longer statistically distinguishable from zero for logarithmized carbon intensities larger than two. Moreover, sufficient data mass exists for carbon intensities beyond two.

\subsection{Robustness: Additional Interactions}

We estimated four additional variants of our main model, differentiated only by an additional interaction term between unilateral implementation and, alternately, corruption, democracy, GDP, and project size (using different measures). Most importantly, the interaction between unilateral implementation and carbon intensity is robust across these models. While statistical significance levels vary somewhat, the signs on the interaction between unilateral implementation and carbon intensity are consistently negative.

\footnotetext{
${ }^{26}$ The simulations were implemented using Fred Boehmke's grinter program in Stata.
} 
First, we considered the interactive effect of unilateral implementation and corruption. We found some evidence of an interaction in the full sample, though the sign was unexpected: as corruption increases, the advantage of unilateral implementation decreases. This seems to indicate that domestic project developers suffer more from corruption if they do not cooperate with foreign investors. Further research is warranted, though we caution that the confidence intervals around the estimates are rather wide.

We also considered the effect of unilateral implementation in democracies versus autocracies. We found no interactive effect whatsoever: the sign of the interaction term flips between models and the term itself is never significant. Democratic governance does not appear to condition the difference between contracting modes.

Third, we found that GDP strongly influences the effect of unilateral implementation for four out of six models. Specifically, the effect of unilateral implementation on the supply of private capital is maximized in rich countries. This suggests that shortages of foreign investments in rather wealthy countries are compensated for by unilateral project implementation through domestic project developers. In these countries domestic actors seem to set up projects to sell climate mitigation credits in global carbon markets or to bank them for future use.

Finally, we examined the interactive effect of project size on the unilateral implementation advantage. We find no support for a conditional effect of project size. The interaction effect for the small projects dummy and unilateral implementation is nowhere close to statistical significance.

\subsection{Robustness: Matching and Outlier Analyses}

The matching analysis that we conducted to minimize covariate imbalance between unilateral and bilateral projects also supports our hypothesis. As the appendix shows, unilateral implementation attracts more private capital in countries with low carbon intensities.

Our results are not driven by outliers either. First, we calculated Cook's distance for our main model and eliminated all data points from our dataset with a distance larger than $4 / n$ (Bollen and Jackman, 1990). Second, we reestimated our models while excluding data that has studentized residuals with an absolute value greater than two (Ruppert, 2004). This robustness check lends further credibility to our findings. 


\subsection{Robustness: Subsets and Additional Controls}

We also considered a variety of other robustness tests. First, we excluded the subset of projects that were ultimately canceled or suspended. Focusing only on successful projects, our results remain virtually unchanged. The coefficients change slightly, but the substantive magnitude of these changes is small and the confidence intervals are not much wider. Similarly, we excluded hydroelectricity, wind, biomass, and solar projects, respectively, due to their varying marginal costs. Additionally, we excluded projects focusing on industrial gases, such as HFC and $\mathrm{N} 2 \mathrm{O}$, methane avoidance, and energy efficiency improvements. The results were unchanged.

We also replicated our findings for hydroelectricity, biomass, and wind projects, respectively, so that all other project categories were excluded. The findings are strong for the largest category, hydroelectricity. The results are weak for the other two types, but this may reflect the fact that the sample size decreases to 20 (wind) or 10 (biomass) percent of the sample. Moreover, we also re-estimated our models for subsamples of only methane avoidance and energy efficiency improvement projects, without any change to our main findings despite massive reductions in sample size to about 8.5 and 14 percent, respectively. This suggests that our results hold even across multiple project-type specific subsamples.

To check the sensitivity of our results to particular regions, we not only jointly exclude projects from China and India, but also re-estimate our main models while excluding each of the five regions one-by-one. Our results continue to hold even though in some samples, sample size reduces to less than 15 percent of the data from the original dataset.

Finally, we complement our model with additional control variables. In addition to more detailed project type fixed effects with 23 categories, we account for three year moving averages of a country's population and investment profile as well as trade, industrial output, and foreign direct investment as shares of GDP. We include number of internet users as a proxy for a country's technological advancement. Further, we add gross domestic savings and real interest rates to account for the importance of available domestic capital. Our main results are also robust to these changes. With respect to the additional controls, we find no evidence for trade, inward FDI, industry output, or real interest rates. GDP has a consistently negative effect, suggesting that wealthier countries may offer more lucrative investment opportunities than carbon abatement. Our results 
provide preliminary evidence that higher domestic savings positively affect investment levels and indicate strongly positive effects for corruption and internet usage on investments per ton of $\mathrm{CO} 2$.

\section{Conclusion}

This article has investigated the role of institutional design in drawing private capital to climate mitigation under the CDM. We examined how the availability of private capital depends on the mode of contracting that international institutions promote. We found that unilateral project implementation can increase the supply of private capital if the cost of carbon abatement is high. This means that states should only complement unilateral implementation with bilateral contracts when the cost of climate mitigation is low. Somewhat disappointingly, foreign investors cannot enhance the supply of private capital in contexts where the demand for resources per a ton of carbon dioxide is high.

The article also has an important policy implication: unilateral implementation should remain a central element of the scheme. Initially, the CDM was designed in view of bilateral contracting. However, unilateral implementation has become increasingly popular (Michaelowa, 2007). Our study shows that unilateral implementation is particularly important in countries where the marginal cost of pollution abatement is relatively high. However, the results also caution against excessive optimism. In the most lucrative contexts, unilateral implementation does not significantly increase capital investment relative to the traditional mode of bilateral contracting. These lessons should also be applied to the wide variety of other carbon markets that are currently emerging (World Bank, 2011). Our findings show that their designers should account for investment incentives and political risks in market design. Of particular importance are the interactive effects of the contracting mode and country characteristics. This finding suggests that flexible markets that allow investors to select among multiple contractual models may enhance the efficiency of carbon markets.

The uncertainty regarding the future of the Kyoto Protocol presents a clear danger to the present form of the CDM (Palmer, 2011). While our model cannot speak to this issue, the findings are also applicable to a future carbon credit scheme as long as project implementation is somehow rewarded. Even if developing countries will be rewarded for programs or schemes, they must somehow incentivize foreign and/or domestic project developers, and our model provides some insight into how this can be done. Moreover, we find it improbable that the entire CDM architecture would be dismantled. Even if carbon markets based on Kyoto 
commitments were no longer viable, transaction cost economics suggests that states should retain the most successful features of the CDM and exploit the lessons learned. For these reasons, we believe our model to have relevance in the post-2012 era of climate policy, too.

We have not commented on the imperfect enforcement of international agreements (Axelrod and Keohane, 1985; Downs, Rocke, and Barsoom, 1996; Urpelainen, 2010) in the analysis. One key challenge to applying our model is the difficulty of enforcing international rules under anarchy. The CDM, for example, depends on there being enough demand for carbon credits. The demand for credits is uncertain, however, because the Kyoto commitments themselves are not directly enforceable and depend on expectations about the future viability of the treaty architecture (Palmer, 2011). Our model assumes private investors believe the enforceability of their contracts. So far, carbon markets have achieved this goal because industrialized countries have credibly committed to emissions reductions, but past performance is not a guarantee of future success. According to the international relations literature, the enforceability of a carbon credit scheme depends on robust political support among major powers, regardless of exact institutional design (Steinberg, 2002; Victor, 2011). At the same time, if institutional design increases the cost-effectiveness of carbon markets and creates profitable opportunities for investors, this could bolster domestic political support for the scheme in key countries.

This article also contributes to the study of public-private partnerships in global governance (Bernhagen and Mitchell, 2010; Kaul, 2006). In capitalist societies, markets provide most private goods. However, they are also increasingly important in the provision of public goods, such as climate mitigation. For scholars of international cooperation interested in understanding the role of private capital, new theories and empirical evidence are indispensable. This article develops a theory of the relationship between private capital and climate mitigation. Moreover, it provides systematic empirical evidence in support of the argument. 


\section{References}

Abbott, Kenneth W., and Duncan Snidal. 1998. "Why States Act through Formal International Organizations." Journal of Conflict Resolution 42 (1): 3-32.

Axelrod, Robert, and Robert O. Keohane. 1985. "Achieving Cooperation under Anarchy: Strategies and Institutions." World Politics 38 (1): 226-254.

Balatbat, Maria C. A., Emily Findlay, and David G. Carmichael. 2012. "Performance Risk Associated with Renewable Energy CDM Projects." Journal of Management in Engineering 28 (1): 51-58.

Barrett, Scott. 2003. Environment and Statecraft: The Strategy of Environmental Treaty-Making. Oxford: Oxford University Press.

Barrett, Scott. 2007. Why Cooperate? The Incentive to Supply Global Public Goods. Oxford: Oxford University Press.

Bayer, Patrick, and Johannes Urpelainen. 2013. "External Sources of Clean Technology: Evidence from the Clean Development Mechanism.” Review of International Organizations 8 (1): 81-109.

Bernhagen, Patrick, and Neil J. Mitchell. 2010. "The Private Provision of Public Goods: Corporate Commitments and the United Nations Global Compact." International Studies Quarterly 54 (4): 1175-1187.

Binder, Seth, and Eric Neumayer. 2005. "Environmental Pressure Group Strength and Air Pollution: An Empirical Analysis." Ecological Economics 55 (4): 527-538.

Bollen, Kenneth A., and Robert W. Jackman. 1990. "Regression Diagnostics: An Expository Treatment of Outliers and Influential Cases." In Modern Methods of Data Analysis, ed. John Fox, and J. Scott Long. Newbury Park: Sage.

Brinkman, Marcel. 2009. "Incentivizing Private Investment in Climate Change Mitigation." In Climate Finance: Regulatory and Funding Strategies for Climate Change and Global Development. New York: New York University Press.

Bueno de Mesquita, Bruce, Alastair Smith, Randolph M. Siverson, and James D. Morrow. 2003. The Logic of Political Survival. Cambridge: MIT Press.

Büthe, Tim, and Helen V. Milner. 2008. "The Politics of Foreign Direct Investment into Developing Countries: Increasing FDI through International Trade Agreements?" American Journal of Political Science 52 (4): 741-762.

Büthe, Tim, and Walter Mattli. 2011. The New Global Rulers: The Privatization of Regulation in the World Economy. Princeton: Princeton University Press.

Castro, Paula. 2012. "Does the CDM Discourage Emission Reduction Targets in Advanced Developing Countries?" Climate Policy 12 (2): 198-218.

Cheibub, José Antonio, Jennifer Gandhi, and James Raymond Vreeland. 2010. "Democracy and Dictatorship Revisited." Public Choice 143 (1-2): 67-101. 
Dinar, Ariel, Shaikh Mahfuzur Rahman, Donald F. Larson, and Philippe Ambrosi. 2011. "Local Actions, Global Impacts: International Cooperation and the CDM.” Global Environmental Politics 11 (4): 108133.

Downs, George W., David M. Rocke, and Peter N. Barsoom. 1996. "Is the Good News about Compliance Good News about Cooperation?" International Organization 50 (3): 379-406.

Gulbrandsen, Lars H. 2004. "Overlapping Public and Private Governance: Can Forest Certification Fill the Gaps in the Global Forest Regime?" Global Environmental Politics 4 (2): 75-99.

Henisz, Witold J. 2002. "The Institutional Environment for Infrastructure Investment." Industrial and Corporate Change 11 (2): 355-389.

Iacus, Stefano M., Gary King, and Giuseppe Porro. 2012. "Causal Inference without Balance Checking: Coarsened Exact Matching." Political Analysis 20 (1): 1-24.

Jensen, Nathan M. 2003. "Democratic Governance and Multinational Corporations: Political Regimes and Inflows of Foreign Direct Investment.” International Organization 57 (3): 587-616.

Kaul, Inge. 2006. "Exploring the Policy Space Between Markets and States: Global Public-Private Partnerships." In The New Public Finance: Responding to Global Challenges, ed. Inge Kaul, and Pedro Conceição. New York: Oxford University Press.

Kerner, Andrew. 2009. "Why Should I Believe You? The Costs and Consequences of Bilateral Investment Treaties." International Studies Quarterly 53 (1): 73-102.

Kuik, Onno, Luke Brander, and Richard S.J. Tol. 2009. "Marginal Abatement Costs of Greenhouse Gas Emissions: A Meta-analysis." Energy Policy 37 (4): 1395-1403.

Lin, Tyrone T., Chuan-Chuan Ko, and Hsin-Ni Yeh. 2007. "Applying Real Options in Investment Decisions Relating to Environmental Pollution.” Energy Policy 35 (4): 2426-2432.

Lütken, Søren Ender, and Axel Michaelowa. 2008. Corporate Strategies and the Clean Development Mechanism: Developing Country Financing for Developed Country Commitments? Northampton: Edward Elgar.

MacKenzie, Ian A., Markus Ohndorf, and Charles Palmer. 2012. "Enforcement-Proof Contracts with Moral Hazard in Precaution: Ensuring 'Permanence' in Carbon Sequestration." Oxford Economic Papers 64 (2): $350-374$.

Maraseni, Tek Narayan, and Gao Xinquan. 2011. "An Analysis of Chinese Perceptions of Unilateral Clean Development Mechanism (uCDM) Projects.” Environmental Science and Policy 14 (3): 339-346.

Markusen, James R. 2001. "Contracts, Intellectual Property Rights, and Multinational Investment in Developing Countries.” Journal of International Economics 53 (1): 189-204.

Michaelowa, Axel. 2007. "Unilateral CDM: Can Developing Countries Finance Generation of Greenhouse Gas Emission Credits on Their Own?" International Environmental Agreements 7 (1): 17-34.

Morgan, Stephen L., and Christopher Winship. 2010. Counterfactuals and Causal Inference: Methods and Principles for Social Research. New York: Cambridge University Press. 
Palmer, Charles. 2011. "Property Rights and Liability for Deforestation under REDD+: Implications for 'PermanenceâĂŹ in Policy Design.” Ecological Economics 70 (4): 571-576.

Rosendal, G. Kristin, and Steinar Andresen. 2011. "Institutional Design for Improved Forest Governance through REDD: Lessons from the Global Environment Facility.” Ecological Economics 70 (11): 19081915.

Ruppert, David. 2004. Statistics and Finance: An Introduction. New York: Springer.

Sell, Susan K. 2003. Private Power, Public Law: The Globalization of Intellectual Property Rights. New York: Cambridge University Press.

Steinberg, Richard H. 2002. "In the Shadow of Law or Power? Consensus-Based Bargaining and Outcomes in the GATT/WTO.” International Organization 56 (2): 339-374.

Streck, Charlotte, and Jolene Lin. 2008. "Making Markets Work: A Review of CDM Performance and the Need for Reform.” European Journal of International Law 19 (2): 409-442.

Tallman, Stephen B. 1992. "A Strategic Management Perspective on Host Country Structure of Multinational Enterprises." Journal of Management 18 (3): 455-471.

Urpelainen, Johannes. 2010. "Enforcement and Capacity Building in International Cooperation." International Theory 2 (1): 32-49.

Victor, David G. 2011. Global Warming Gridlock: Creating More Effective Strategies for Protecting the Planet. New York: Cambridge University Press.

Williamson, Oliver E. 1979. "Transaction-Cost Economics: The Governance of Contractual Relations." Journal of Law and Economics 49 (1): 173-196.

Winkelman, Andrew G., and Michael R. Moore. 2011. "Explaining the Differential Distribution of the Clean Development Mechanism Projects Across Host Countries.” Energy Policy 39 (3): 1132-1143.

World Bank. 2011. State and Trends of the Carbon Market. Washington DC: World Bank. 


\section{Differences in Investment Thresholds}

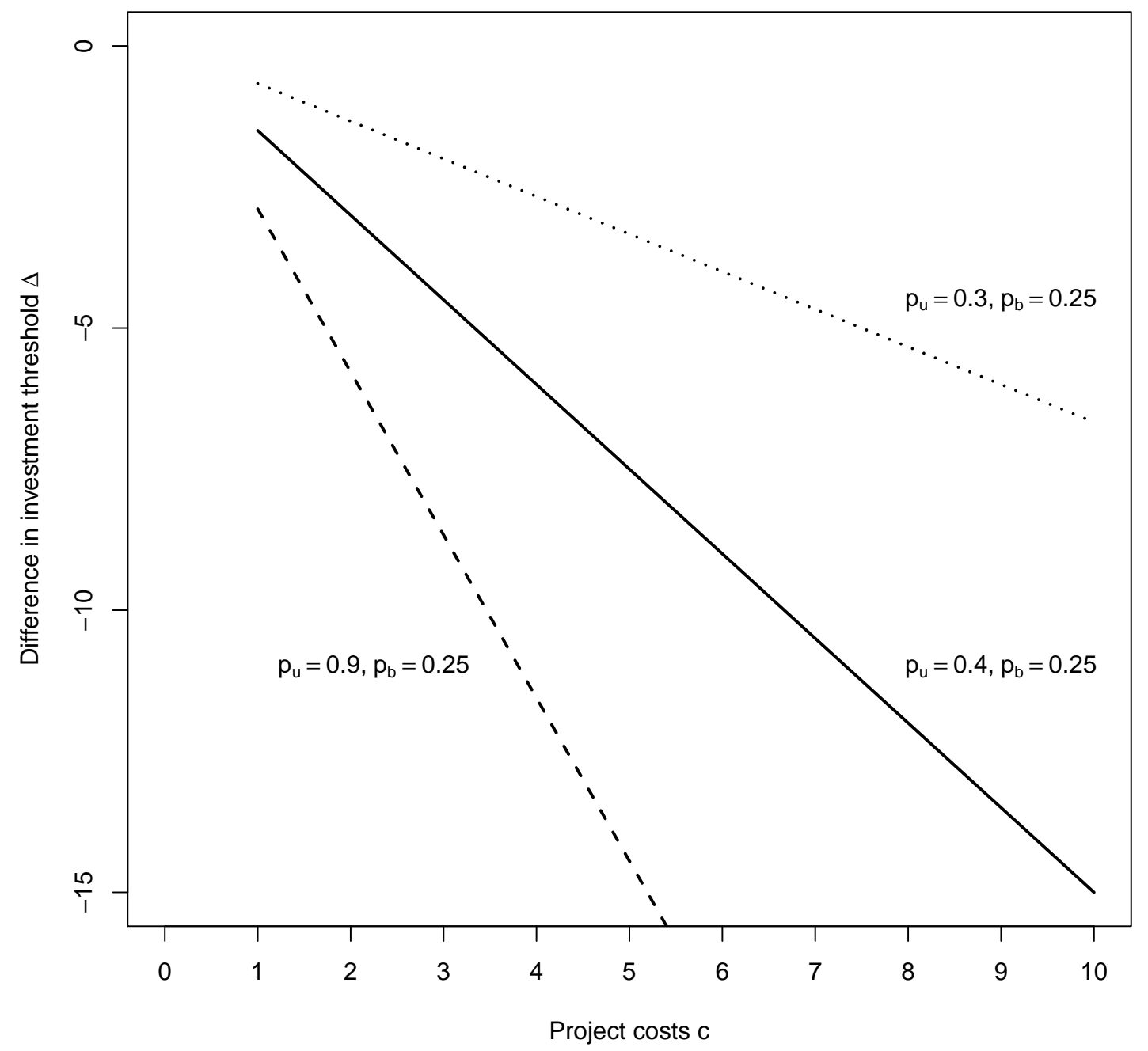

Figure 1: The $y$-axis shows how much the investment threshold for profits $\pi$ decreases if unilateral implementation replaces bilateral contracting. More negative values suggest larger advantages of unilateral over bilateral implementation. The success probability for bilateral contracting is held constant at $p_{b}=0.25$, but the success probability of unilateral contracting varies: $p_{u}=0.9$ for the dashed line, $p_{u}=0.6$ for the solid line, and $p_{u}=0.3$ for the dotted line. As the project cost $c$ increases, the decrease in the investment threshold also becomes larger. 

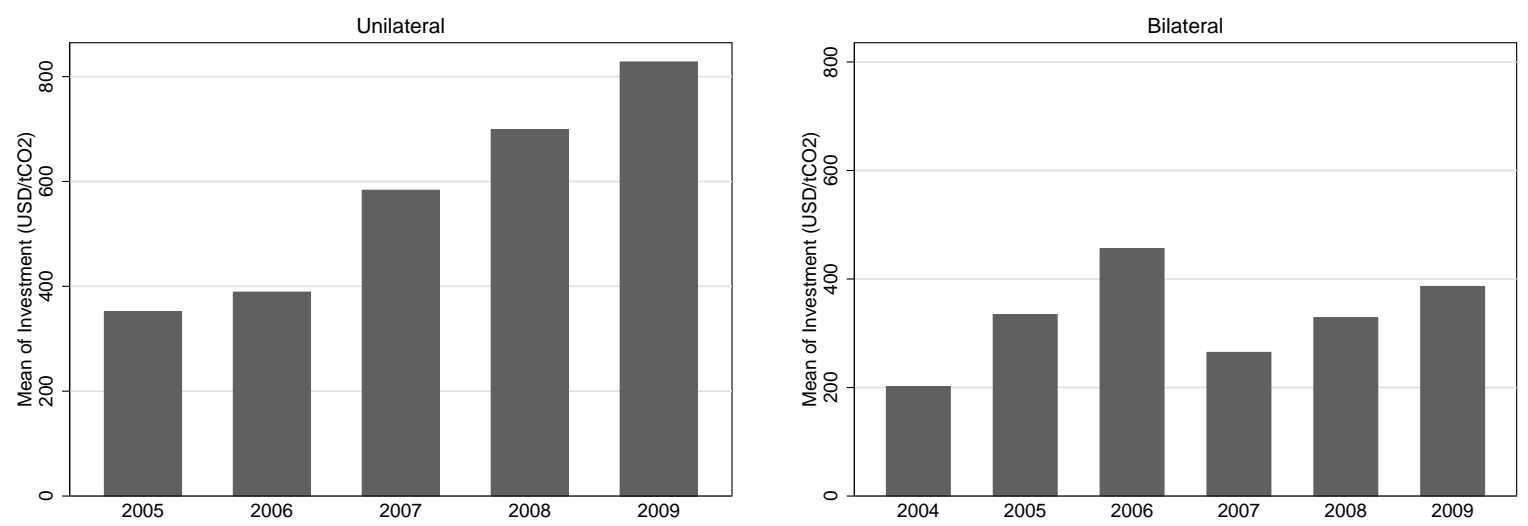

Figure 2: Annual mean of investment (USD/tCO2) by contracting mode. 

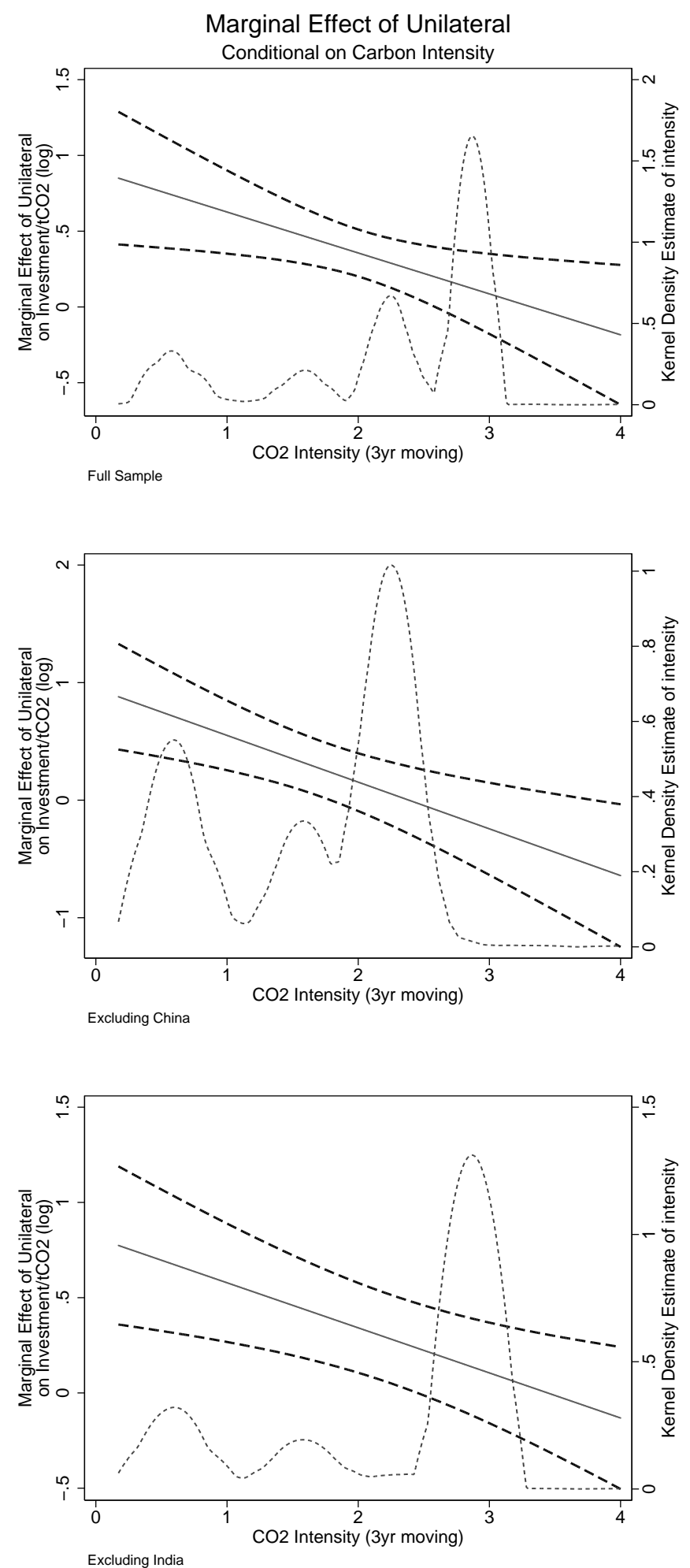

Figure 3: Marginal effects. The top graph shows the full sample, the middle graph the sample without China, and the bottom graph the sample without India. The straight line shows the estimated difference between unilateral and bilateral implementation on investment per ton of carbon dioxide emissions. The dashed lines are $95 \%$ confidence intervals. 


\begin{tabular}{|c|c|c|c|c|c|c|}
\hline & $\begin{array}{c}(1) \\
\text { Model }\end{array}$ & $\begin{array}{c}(2) \\
\text { Model }\end{array}$ & $\begin{array}{c}(3) \\
\text { Model }\end{array}$ & $\begin{array}{c}(4) \\
\text { Model }\end{array}$ & $\begin{array}{c}(5) \\
\text { Model }\end{array}$ & $\begin{array}{c}(6) \\
\text { Model }\end{array}$ \\
\hline Unilateral & $\begin{array}{c}0.82^{* * *} \\
(0.25)\end{array}$ & $\begin{array}{c}0.90^{* * *} \\
(0.23)\end{array}$ & $\begin{array}{c}0.96^{* * *} \\
(0.25)\end{array}$ & $\begin{array}{c}0.95^{* * *} \\
(0.24)\end{array}$ & $\begin{array}{c}0.73^{* * *} \\
(0.25)\end{array}$ & $\begin{array}{c}0.81^{* * *} \\
(0.22)\end{array}$ \\
\hline $\mathrm{CO} 2$ Intensity (3yr moving) & $\begin{array}{c}0.08 \\
(0.06)\end{array}$ & $\begin{array}{c}0.16 \\
(0.10)\end{array}$ & $\begin{array}{c}0.26^{* * *} \\
(0.07)\end{array}$ & $\begin{array}{c}0.23^{* * *} \\
(0.07)\end{array}$ & $\begin{array}{c}0.05 \\
(0.06)\end{array}$ & $\begin{array}{c}0.08 \\
(0.11)\end{array}$ \\
\hline Unilateral x CO2 Intensity & $\begin{array}{l}-0.22^{* *} \\
(0.11)\end{array}$ & $\begin{array}{c}-0.27^{* *} \\
(0.11)\end{array}$ & $\begin{array}{c}-0.43^{* * *} \\
(0.12)\end{array}$ & $\begin{array}{c}-0.40^{* * *} \\
(0.12)\end{array}$ & $\begin{array}{c}-0.19^{* *} \\
(0.09)\end{array}$ & $\begin{array}{c}-0.24^{* * *} \\
(0.08)\end{array}$ \\
\hline Corruption (3yr moving) & & $\begin{array}{c}0.17 \\
(0.12)\end{array}$ & & $\begin{array}{c}0.11 \\
(0.12)\end{array}$ & & $\begin{array}{c}0.16 \\
(0.14)\end{array}$ \\
\hline Democracy & & $\begin{array}{c}0.09 \\
(0.10)\end{array}$ & & $\begin{array}{c}0.01 \\
(0.17)\end{array}$ & & $\begin{array}{l}-0.04 \\
(0.20)\end{array}$ \\
\hline GDP (3yr moving, log) & & $\begin{array}{l}-0.07 \\
(0.05)\end{array}$ & & $\begin{array}{l}-0.04 \\
(0.07)\end{array}$ & & $\begin{array}{l}-0.07 \\
(0.05)\end{array}$ \\
\hline Constant & $\begin{array}{c}3.54^{* * *} \\
(0.21)\end{array}$ & $\begin{array}{c}4.84^{* * *} \\
(1.23)\end{array}$ & $\begin{array}{c}3.22^{* * *} \\
(0.18)\end{array}$ & $\begin{array}{l}3.92^{* *} \\
(1.66)\end{array}$ & $\begin{array}{c}3.46^{* * *} \\
(0.27)\end{array}$ & $\begin{array}{c}4.80^{* * *} \\
(1.23)\end{array}$ \\
\hline Year Effects & Yes & Yes & Yes & Yes & Yes & Yes \\
\hline Project Type Effects & Yes & Yes & Yes & Yes & Yes & Yes \\
\hline $\begin{array}{l}\text { Observations } \\
R^{2}\end{array}$ & $\begin{array}{l}3749 \\
0.503\end{array}$ & $\begin{array}{l}3749 \\
0.508\end{array}$ & $\begin{array}{l}1810 \\
0.535\end{array}$ & $\begin{array}{l}1810 \\
0.536\end{array}$ & $\begin{array}{l}2926 \\
0.546\end{array}$ & $\begin{array}{l}2926 \\
0.551\end{array}$ \\
\hline $\begin{array}{l}\text { Standard errors in parentheses } \\
\text { Dependent Variable: Investment/tC } \\
\text { Models (3-4) exclude China. Mode } \\
\text { All models: Robust SEs clustered } \mathrm{t} \\
{ }^{*} p<0.10,{ }^{* *} p<0.05,{ }^{* * *} p<0\end{array}$ & $\begin{array}{l}02 \\
\text { s (5-6) excl } \\
y \text { country } \\
.01\end{array}$ & de India & & & & \\
\hline
\end{tabular}

Table 1: Main results. Our two-part hypothesis states that the coefficient on "Unilateral" should be positive and statistically significant, while the coefficient on "Unilateral x CO2 Intensity" should be negative and statistically significant. 